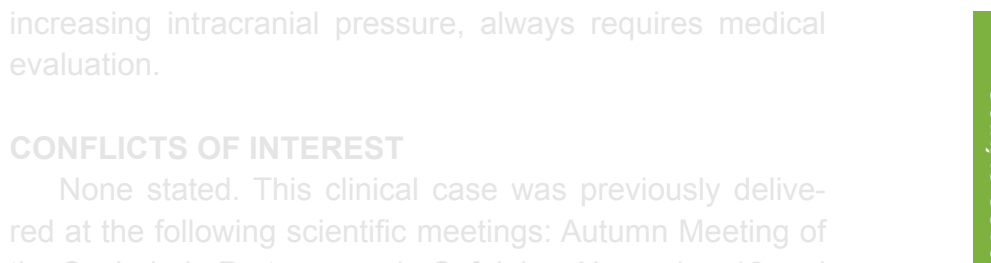

\title{
Protocolo de Actuação Hospitalar na Abordagem de Mordedura de Ofídio
}

\author{
Hospital Protocol for Snakebite Victims Management
}

\author{
Pedro MARQUES DA COSTA ${ }^{1,2}$, Rodrigo SOUSA ${ }^{1}$, Maria LOBO ANTUNES ${ }^{1}$, Sara AZEVEDO ${ }^{1,2}$, Gabriela ARAÚJO E \\ $S A^{1,2}$, Maria do Céu MACHADO 1,2 \\ Acta Med Port 2014 Jan-Feb;27(1):141-145

\section{RESUMO} \\ A mordedura de ofídio venenoso é uma situação rara em Portugal. Quando ocorre em idade pediátrica apresenta maior gravidade \\ e risco de complicações fatais. A actuação protocolada constitui o gold standard of care nos centros internacionais. Neste artigo \\ apresentamos dois casos clínicos de mordedura de ofídio venenoso em idade pediátrica. Baseados na literatura actual, discutimos \\ a actuação clínica tomada e expomos uma proposta de protocolo de actuação hospitalar que visa uma intervenção multidisciplinar e \\ actualizada das equipas médicas envolvidas.
}

Palavras-chave: Antivenenos; Mordeduras de Serpentes; Portugal. 


\section{ABSTRACT}

Venomous snakebites are relatively rare in Portugal. Pediatric victims present with greater severity and are at risk of fatal complications. Clinical management protocols are the gold standard of care worldwide. We report two cases of venomous adder bites in pediatric patients. Based on a literature review we also discuss the clinical management and present a treatment protocol that ensures multidisciplinary and updated practice by medical teams.

Keywords: Antivenins; Snake Bites; Portugal.

\section{Epidemiologia e circunstâncias da mordedura}

As mordeduras de ofídio são responsáveis por cerca de 30 mortes/ano na Europa, ${ }^{1}$ desconhecendo-se a sua incidência em Portugal.

Em Portugal existem três espécies venenosas: víbora cornuda (Vipera latastei), víbora portuguesa (Vipera berus seoanei) e cobra rateira (Malpolon monspessulanus). Destas, a primeira é a detentora do veneno mais activo ${ }^{2}$ encontrando-se dispersa por todo o país (Serras do Gerês, Monchique, Sintra, Vale do Guadiana e Mafra). ${ }^{3}$

$\mathrm{Na}$ idade pediátrica, as mordeduras afectam sobretudo crianças do sexo masculino ${ }^{4,5} \mathrm{com}$ idade média de 6,5 anos, ${ }^{5}$ ocorrendo nos membros superiores em $30-60 \%$ dos casos. ${ }^{4-6}$ Pelo seu menor volume corporal, as crianças são particularmente susceptíveis ao envenenamento. ${ }^{3,7}$

\section{Manifestações clínicas}

Inicialmente verifica-se hiperactividade simpática (náuseas, taquicardia, vasoconstrição e sudorese $)^{2-4,8,9}$ não directamente relacionada com o envenenamento. ${ }^{3}$

\section{Manifestações locais}

Da mordedura das presas inoculadoras resultam tipicamente dois pontos eritematosos distando aproximadamente $1 \mathrm{~cm} .{ }^{3,9} \mathrm{Na}$ primeira hora surge dor (90\% dos casos), eritema e edema podendo associar-se bolhas sero-hemorrágicas, linfangite e equimoses ${ }^{3,9} \mathrm{~A}$ inoculação de veneno, na ausência de sinais locais nos primeiros 30 minutos, é improvável. ${ }^{3}$

\section{Manifestações sistémicas}

Horas após desenvolvem-se náusea, vómitos e letargia. ${ }^{9}$ Alguns doentes referem sabor metálico, ${ }^{9}$ parestesias periorais e locais. ${ }^{8}$ Manifestações mais graves incluem hipotensão, taquicardia, dificuldade respiratória e alteração do estado de consciência. ${ }^{9}$

\section{Complicações}

A figura 1 lista as principais complicações da mordedura de víbora. O veneno é essencialmente hematotóxico. Coagulopatia de consumo, desfibrinogenação e defeitos plaquetários podem resultar em hemorragias gastrintestinais, geniturinárias e do sistema nervoso central. ${ }^{5,8} \mathrm{~A}$ morte, rara, é frequentemente provocada por sepsis e/ou discrasia hemorrágica. $3,2,10$

\section{Caso clínico 1}

Criança de oito anos, sexo masculino, saudável, mordida por víbora cornuda no segundo dedo da mão direita (Fig. 2). À observação em hospital distrital após uma hora apresentava flictena e edema no local da mordedura, sem outras alterações, tendo alta sob antibioticoterapia. Internada 12 horas após a mordedura por vómitos e progressão proximal do edema (Fig. 3). Transferida para o Hospital de Santa Maria (HSM) 27 horas após a mordedura, onde se administrou soro antiofídico (por grau Il de gravidade), com melhoria clínica progressiva nos quatro dias seguintes.

\section{Caso clínico 2}

Adolescente de 13 anos, sexo masculino, saudável, mordido por víbora cornuda no primeiro dedo do pé direito. Recorreu ao serviço de urgência de um hospital privado, apresentando ferida punctiforme com edema discreto, sem outras alterações. Transferido para o HSM 3,5 horas após a mordedura por progressão proximal do edema (Fig. 4A). Por agravamento do edema com dor (transitando para grau II) (Fig. 4B), foi administrado soro antiofídico, apresentando melhoria clínica progressiva nos 3 dias seguintes.

\section{Protocolo de Actuação \\ Actuação pré-hospitalar}

A actuação pré-hospitalar incide no resgate, imobilização e transporte rápido à unidade hospitalar mais próxima. ${ }^{11}$ (Fig. 1). Estão contra-indicados: crioterapia, ${ }^{12}$ incisão com sucção mecânica ${ }^{20}$ e torniquetes venosos. Os últimos reservam-se a circunstâncias de atraso no transporte, neurotoxicidade ou envenenamento sistémico catastrófico. ${ }^{12-14}$

\section{Actuação hospitalar}

A actuação inicial visa a estabilização das funções vitais, exame objectivo detalhado e estabelecimento de acessos venosos para colheita sanguínea, administração de soro antiofídico (SAO) ou fluidos (Tabela 1)..$^{9,14,15} \mathrm{~A}$ abordagem subsequente segue a classificação de gravidade de envenenamento consoante as manifestações clínicas locais e sistémicas (Tabela 1). É mandatória articulação imediata com centro terciário, equacionando transferência mediante justificação clínica.

\section{Administração de SAO}

A administração de SAO reserva-se ao grau II e III.,9,16,17 Ainda que não suportada por estudos controlados, a sua eficácia parece similar à determinada em adultos. ${ }^{17}$

O SAO disponível em Portugal (Viperfav ${ }^{\circledR}$ ) tem eficácia máxima nas primeiras 10 horas após mordedura (Fig. 1). ${ }^{16,18}$ Uma única administração parece controlar qualquer grau de envenenamento sem necessidade de ajuste ao peso visto o efeito neutralizante depender da quantidade de veneno inoculado. ${ }^{17,17}$

Embora as reaç̧ões alérgicas sejam frequentes (2$5 \%$, na ausência de antecedentes de hipersensibilidade, a 


\section{Resgate da vítima da área de perigo}

2. Imobilização do membro em posição gravitacional neutra (ao nível do coração)

3. Limpeza da ferida e aplicação de penso (evitar soluções alcoólicas ou corantes)

4. Identificação do ofídio sem manipulação directa

5. Transporte rápido ao hospital mais próximo, em posição de imobilização completa e com monitorização de sinais locais e sistémicos.

- Crioterapia
- Incisão com sucção mecânica
çorniquetes ou outras aplica-
a atrasar o envenenamento
sistémico

ACTUAÇÃO HOSPITALAR

\begin{tabular}{|c|c|c|}
\hline \multicolumn{3}{|c|}{ ACTUAÇÃO HOSPITALAR } \\
\hline \multicolumn{3}{|c|}{ ABORDAGEM INICIAL } \\
\hline \multirow{7}{*}{$\begin{array}{l}\text { - Estabilização das funções vitais (ABC) } \\
\text { - Canalização de duas veias priféricas e avaliação analítica } \\
\text { - Exame físico detalhado (sinais locais e possíveis complicações } \\
\text { - Mistémicas) } \\
\text { - Marcação dos limites dos sinais inflamatórios locais e a } \\
\text { reavaliação seriada (15 - } 30 \text { min) } \\
\text { - História clínica breve (incluindo local, hora da mordedura e tipo } \\
\text { de ofídio) } \\
\text { - Articulação com centro terciário }\end{array}$} & \multicolumn{2}{|c|}{ Exames complementares de diagnóstico } \\
\hline & Essencial & Se possível \\
\hline & Hemograma completo & AST/ALT, CPK \\
\hline & INR, APTT, TP Fibrinogénio & Gasometria \\
\hline & D-dímero e PDFs & Tipagem \\
\hline & $\begin{array}{l}\text { lonograma } \\
\text { Creatinina Ureia }\end{array}$ & Urina tipo II \\
\hline & $\begin{array}{l}\text { Creatınına, Urela } \\
\text { Electrocardiograma }\end{array}$ & \\
\hline
\end{tabular}

\section{ESTRATIFICAÇÃO DE GRAVIDADE}

\begin{tabular}{|c|c|c|c|}
\hline Classificação & Gravidade & Manifestações locais & Manifestações locais \\
\hline Grau 0 & "Mordedura branca" & $\begin{array}{c}\text { Ausentes } \\
\text { (apresenta marca de mordedura) }\end{array}$ & Ausentes \\
\hline Grau I & Ligeira & $\begin{array}{l}\text { Dor, edema eritrema e/ou equimose } \\
\text { localizados e não progressivos }\end{array}$ & Ausentes \\
\hline Grau II & Moderada & $\begin{array}{l}\text { Dor, edema eritrema e/ou equimose com } \\
\text { progressão regional para os membros } \\
\text { superiores/inferiores }\end{array}$ & $\begin{array}{l}\text { Náuseas, vómitos, hipotensão, } \\
\text { parestesias periorais, dor abdominal }\end{array}$ \\
\hline Grau III & Grave & $\begin{array}{l}\text { Dor, edema eritrema e/ou equimose } \\
\text { rapidamente progressivos com } \\
\text { envolvimento do tronco }\end{array}$ & $\begin{array}{l}\text { Choque, falência de orgão, anafilaxia, } \\
\text { alterações do estado de consciência, } \\
\text { taquicardia, dispneia, coagulopatia grave }\end{array}$ \\
\hline
\end{tabular}

\section{ABORDAGEM SUBSEQUENTE}

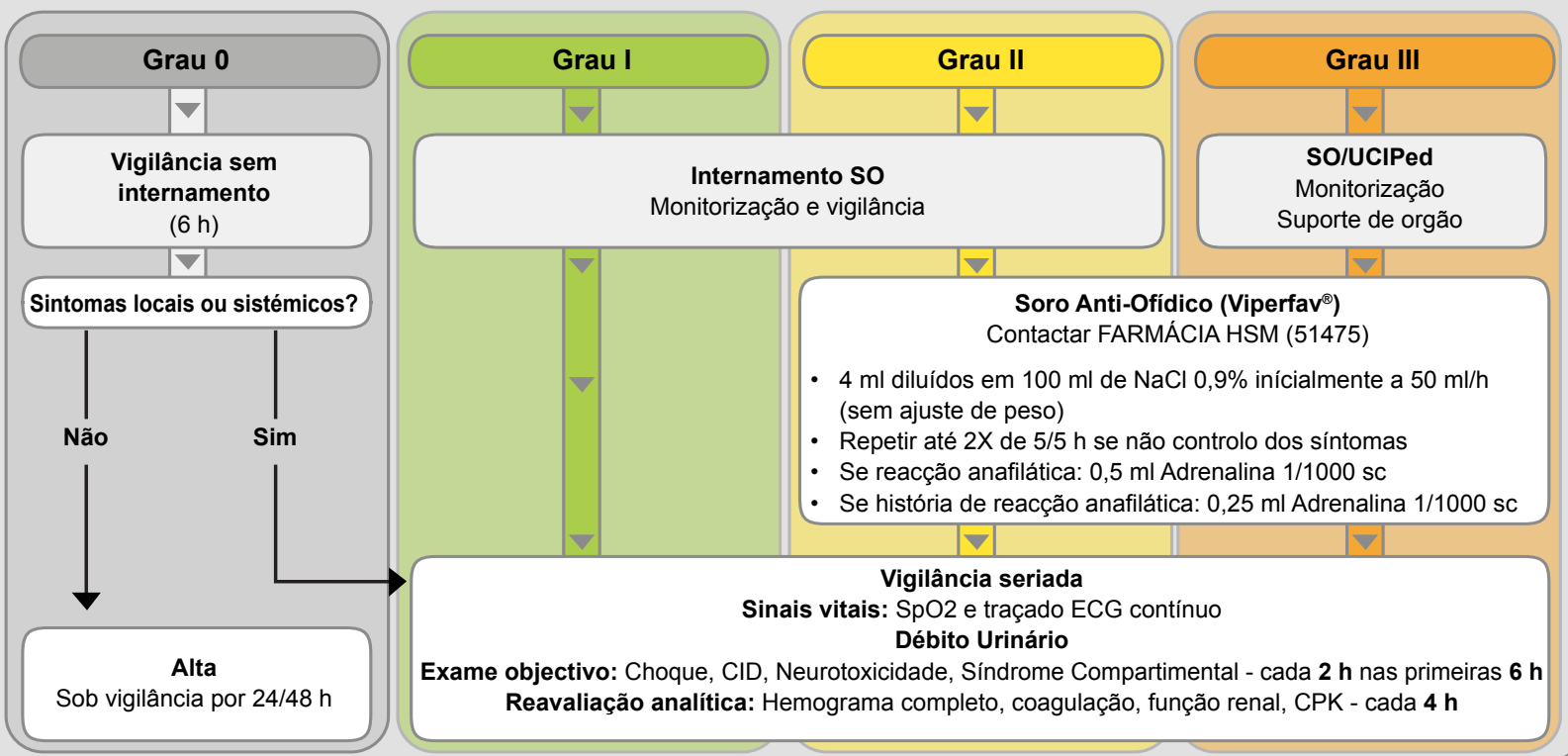

Figura 1 - Mordedura de ofídio - Protocolo de atuação em urgência pediátrica

pré-medicação com adrenalina, anti-histamínicos ou corticosteróides não é recomendada. ${ }^{19-21}$

\section{Avaliação subsequente}

Para as mordeduras brancas (Grau 0) estão recomendadas 12 horas de observação ( 6 horas em espécies pouco venenosas e na ausência completa de indícios de envenenamento). ${ }^{22-24}$

Devido ao risco de agravamento nas primeiras horas (57\% em idade pediátrica), ${ }^{5}$ exige-se internamento em Sala de Observações (SO) no grau I ou II e, admissão imediata em Unidade de Cuidados Intensivos (UCIPed) no grau III. A 


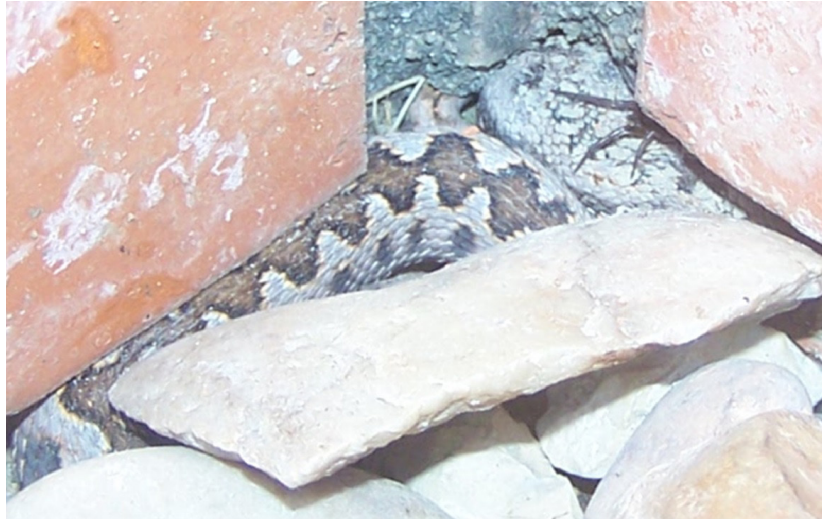

Figura 2 - Fotografia da víbora captada por familiar do doente imediatamente após a mordedura

monitorização envolve: avaliação contínua dos sinais vitais, traçado electrocardiográfico, débito urinário e exame físico seriado, orientado para as complicações sistémicas. ${ }^{9,14,15} \mathrm{~A}$ avaliação analítica repete-se a cada 8 a $12 \mathrm{~h}(6$ horas no caso de coagulopatia) e após cada infusão de SAO., ${ }^{9,14} \mathrm{Nes}-$ tes casos, um mínimo 24 horas de observação é mandatória podendo a alta ser protelada perante critérios de mau prognóstico. $9,11,19$

\section{Medidas de suporte}

Analgesia apropriada com paracetamol/anti-inflamatórios não esteróides tem menor risco de mascarar sintomas de neurotoxicidade, sendo a hipoxemia um sinal precoce

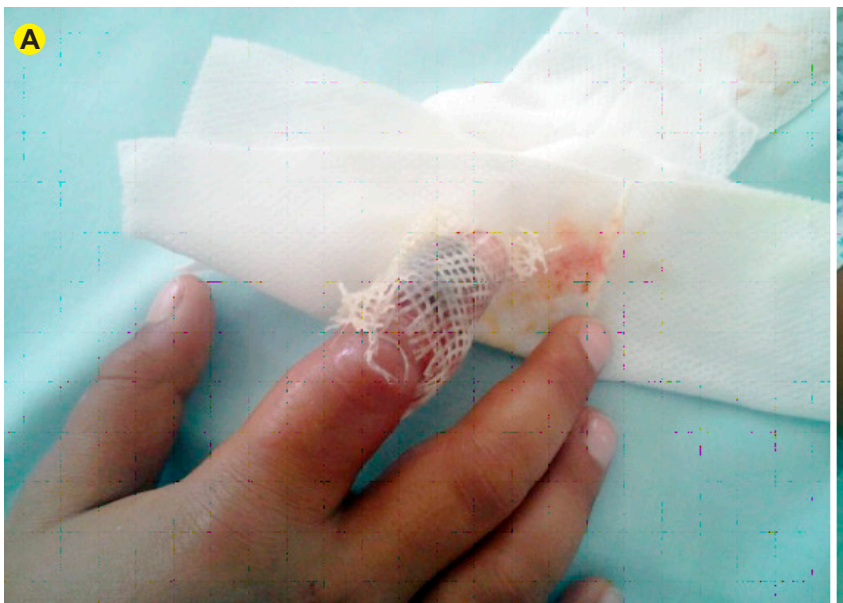

Figura $3 \mathrm{~A}$ - Flictena e edema do $2^{\circ}$ dedo da mão direita Figura 3B - Progressão proximal do edema ao antebraço
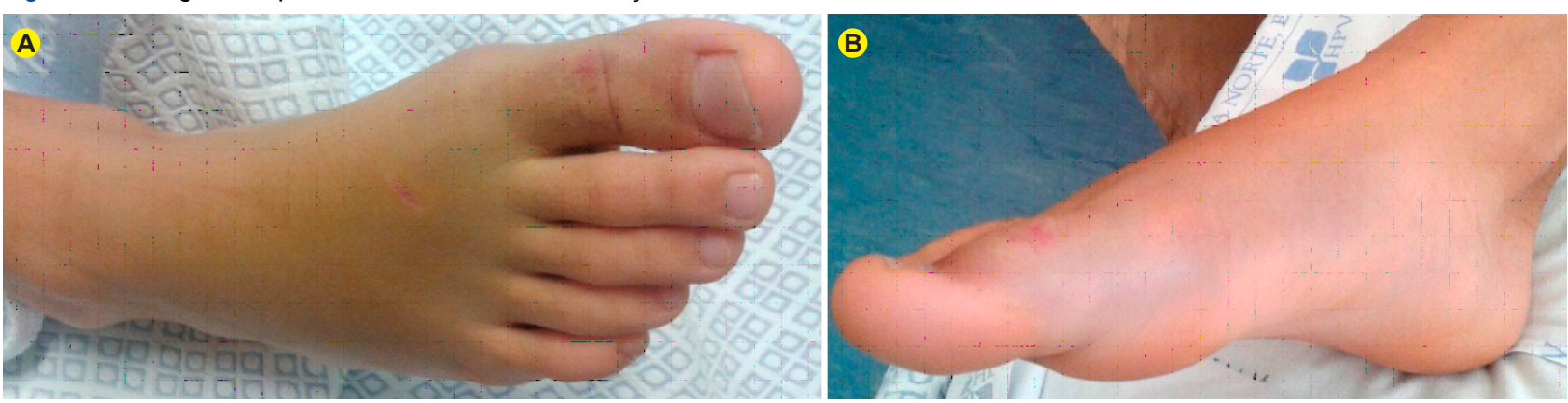

Figura $4 \mathrm{~A}$ - Ferida punctiforme e edema do $1^{\circ}$ dedo do pé direito

Figura 4B - Progressão proximal do edema ao pé direito

que obriga a avaliação e protecção da via aérea se indicado. ${ }^{9,25}$

\section{Complicações}

A infecção bacteriana constitui umas das complicações locais. ${ }^{13} \mathrm{~A}$ prática internacional tem sido de não iniciar antibioticoterapia na ausência de evidência clinica e microbiológica de infecção. ${ }^{9,14}$ Quando iniciada, privilegia-se amoxicilina/clavulanato nos graus I e II. ${ }^{11}$ No grau III, estudos em adultos sugerem piperacilina-tazobactan ${ }^{11}$. Se indicado realiza-se imunização anti-tetânica. ${ }^{14}$

A necrose tecidual (13-20\%) pode exigir desbridamento cirúrgico/amputação. ${ }^{26}$ Ainda que menos frequente a síndrome compartimental $(1,8-9,1 \%)$ exige avaliação seriada. $22,26,27$

\section{Critérios de mau prognóstico}

São factores preditores de envenenamento grave: mordedura no membro superior, sexo feminino, dor violenta e precoce, trombocitopénia ( $\left.\leq 100000 \times 10^{6} / \mathrm{L}\right) ;$ AST $\geq 50 \mathrm{IU} / \mathrm{L}$ e equimoses. ${ }^{5,6,28}$

\section{Critérios de alta}

A alta deve ocorrer na ausência clínica e analítica de progressão do envenenamento (por $24 \mathrm{~h}$ ) com controlo analgésico adequado. Sugere-se limitação da actividade física e vigilância por 72 horas. ${ }^{15,27}$

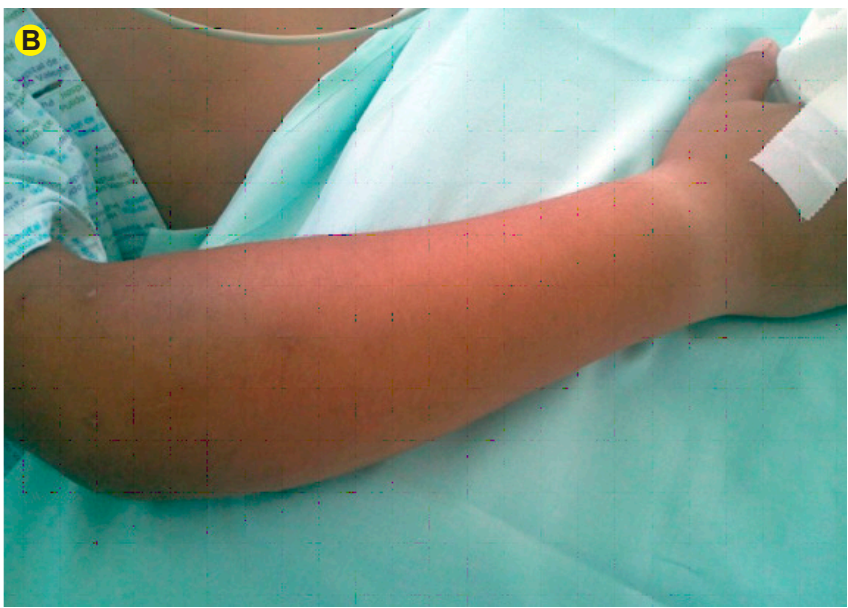


Tabela 1 - Complicações do envenenamento por víbora (adaptado de Ozay et al ${ }^{5}$ )

Complicação

Necrose tecidual / Infecção

Síndrome compartimental

Coagulação intravascular disseminada

Hematológicas

Neurológicas

Cardiovasculares

Hepáticas

Infecção
Incidência

$13 \%$

$9,1 \%$

$9,1 \%$

$6,4 \%$

$5,2 \%$

$3,9 \%$

$1,3 \%$

ND

ND: não discriminado.

\section{CONCLUSÃO}

O envenenamento por ofídio é raro em Portugal mas reveste-se de consequências clínicas potencialmente graves em idade pediátrica. O gold standard of care baseia-se na implementação de protocolos de actuação multidisciplinar baseados na evidência e na formação e actualização das equipas médicas envolvidas.

\section{REFERÊNCIAS}

1. Chippaux JP. Snake-bites: appraisal of the global situation. Bull World Health Organ. 1998;76:515-24.

2. Gonzaga R. Mordeduras e picadas por animais da fauna portuguesa. Porto: Laboratórios BIAL; 1985.

3. Marta MJ, Oliveira A, Saavedra JA. Mordedura de víbora - situação potencialmente grave. Med Inter. 2005;12.

4. Matteucci MJ, Hannum JE, Riffenburgh RH, Clark RF. Pediatric sex group differences in location of snakebite injuries requiring antivenom therapy. J Med Toxicol. 2007;3:103-6.

5. Ozay G, Bosnak M, Ece A, Davutoglu M, Dikici B, Gurkan F, et al. Clinical characteristics of children with snakebite poisoning and management of complications in the pediatric intensive care unit. Pediatr Int. 2005;47:669-75.

6. Claudet I, Gurrera E, Marechal C, Cordier L, Honorat R, Grouteau E. Morsures de vipères chez l'enfant. Arch Pediatrie. 2011;18:1278-83.

7. Mata Zubillaga D, Iglesias Blázquez C, Lobo Martínez P, Naranjo Vivas D. Lesiones por mordedura de víbora. An Pediatr. 2011;74:286-8.

8. Salluh. Mordedura de víbora - Letalidade potencial: A propósito de um caso clínico. Int Clin Med. 2008. [consultado em 2013 jan 5]. Disponível em: http://www.medcenter.com/medscape/content.aspx? id=12496\&langType $=1046$

9. Gold BS, Dart RC, Barish RA. Bites of venomous snakes. N Engl J Med. 2002;347:347-56.

10. Chen CM, Wu KG, Chen CJ, Wang CM. Bacterial infection in association with snakebite: a 10-year experience in a northern Taiwan medical center. J Microbiol Immunol Infect. 2011;44:456-60.

11. Stewart CJ. Snake bite in Australia: first aid and envenomation management. Accid Emerg Nurs. 2003;11:106-11.

12. McKinney PE. Out-of-hospital and interhospital management of crotaline snakebite. Ann Emerg Med. 2001;37:168-74.

13. Burgess JL, Dart RC, Egen NB, Mayersohn M. Effects of constriction bands on rattlesnake venomabsorption: a pharmacokinetic study. Ann Emerg Med. 1992;21:1086-93.

14. Juckett G, Hancox JG. Venomous snakebites in the United States: management review and update. Am Fam Physician. 2002;65:1367-74.

\section{CONFLITOS DE INTERESSE}

Os autores não declararam quaisquer conflitos de interesse na realização do presente trabalho.

\section{FONTES DE FINANCIAMENTO}

Os autores não declararam a existência de quaisquer fontes de financiamento na realização do presente trabaIho.

15. Januário L, Simões J. Mordedura por ofídeos: Implicações clínicas e terapêuticas - proposta de actuação; Protocolos do serviço de urgência. Coimbra: Hospital Pediátrico de Coimbra; 2005.

16. Sanofi Pasteur MSD, VIPERFAV® - Resume des Caracteristiques du Produit. Dernier rectficatif d'AMM: 22/02/2112.

17. Schmidt JM. Antivenom therapy for snakebites in children: is there evidence? Curr Opin Pediatr. 2005;17:233-8.

18. Boels D, Hamel JF, Bretaudeau Deguigne M, Harry P.European viperen venomings: assessment of viperfav ${ }^{\mathrm{TM}}$ and other symptomatic treatments. ClinToxicol. 2012;50:189-96.

19. Isbister GK. Snake bite: a current approach to management. Aust Prescr. 2006;29:125-9.

20. Lalloo DG, Theakston RD. Snake anti venoms. J ClinToxicol. 2003;41:277-90;317-27.

21. Dart RC, McNally J. Efficacy, safety and use of snake anti venoms in theUnited States. Ann Emerg Med. 2001;37:181-8.

22. Evers LH, Bartscher T, Lange T, Mailänder P. Adderbite: an uncommon cause of compartment syndrome in northern hemisphere. Scand J Trauma Resusc Emerg Med. 2010;18:50.

23. Hughes A. Observation of snake bite victims: is twelve hours still necessary? Emerg Med. 2003;15:511-7.

24. Merriam TW, Leopold RS. Evaluation of incision and suction in venom removal. Clin Res. 1960;7:258.

25. Cheng A. Principles of snake bite management worldwide. In: UpToDate 2012.[consultado em 2013 jan 5]. Disponível em: http://www.uptodate. com/contents/principles-of-snake-bite-management-worldwide

26. Laohawiriyakamol S, Sangkhathat S, Chiengkriwate P, Patrapinyokul S. Surgery in management of snake envenomation in children. World $\mathrm{J}$ Pediatr. 2011;7:361-4..

27. Campbell BT, Corsi JM, Boneti C, Jackson RJ, Smith SD, Kokoska ER. Pediatric snakebites: lessons learned from 114 cases. J Pediatr Surg. 2008;43:1338-41.

28. Claudet I, Maréchal C, Gurrera E, Cordier L, Honorat R, Grouteau E. Risk factors for high-grade envenomations after French viper bites in children. Pediatr Emerg Care. 2012;28:650-4. 
Pedro MARQUES DA COSTA, Rodrigo SOUSA, Maria LOBO ANTUNES, Sara AZEVEDO, Gabriela ARAÚJO E SÁ, Maria do Céu MACHADO

\section{Protocolo de Actuação Hospitalar na Abordagem de Mordedura de Ofídio Acta Med Port 2014:27:141-145}

Publicado pela Acta Médica Portuguesa, a Revista Científica da Ordem dos Médicos

Av. Almirante Gago Coutinho, 151

1749-084 Lisboa, Portugal.

Tel: +351218428 215

E-mail: submissao@actamedicaportuguesa.com

www.actamedicaportuguesa.com

ISSN:0870-399X | e-ISSN: 1646-0758

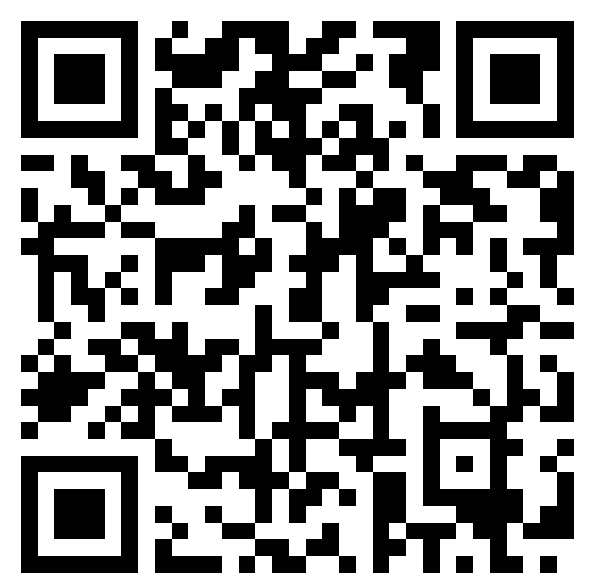

